The Geneva Papers on Risk and Insurance, 17 (No. 62, January 1992), 105-118

\title{
The Fourth Pillar in France in the 1990's: Favourable Trends and Current Obstacles
}

\author{
by Geneviève Reday-Mulvey*
}

\section{Early retirement policy: a brief summing up}

Along with Holland, France, of all industrialised countries, has the lowest activity and employment rates for the 55-64 year age-group. Since 1984, less than half this group has been effectively employed. Germany, the United Kingdom and the United States, to mention but three examples, have been operating early retirement policies for 15 years now, but these have been markedly less vigorous than that of France as can be seen from Table 1 .

Indeed, of all industrialised countries, France has probably pushed furthest ahead with its policy for early retirement. Since 1972 a series of steps have been taken to permit the laying-off of workers at increasingly early ages, up until 1982 at 62 or 60 years while 65 years remained the legal retirement age, and since then throughout the eighties at 58 and 55 years even (when the legal age was brought down to 60 years).

At a time when life expectancy continues to increase and when physical and mental health for many remain sound until very late in life, a lowering of the retirement age has brought forward the social threshold of old age in a fashion which is both premature and irrevocable. For the first time in history the average citizen can expect to spend more time outside employment -23 years in retirement and 19 years on average in training - than within it!

This phenomenon of early retirement has emerged progressively from a somewhat novel consensus shared by enterprise, the government and the community. Its purpose has been to reduce unemployment, and enhance productivity of enterprises through modernisation of the processes of production and restructuring while avoiding the embarassment of rising redundancies...

For enterprise, early retirement has offered a line of lesser resistance obviating a radical review of policies for human resources and in particular for age-group management. For those sections of an enterprise's work force concerned, this lowering of the retirement age has had serious consequences: as the age of 50 years approaches motivation begins to

\footnotetext{
* Economist and Psychosociologist, Research Fellow, International Association for the Study of Insurance Economics.
} 


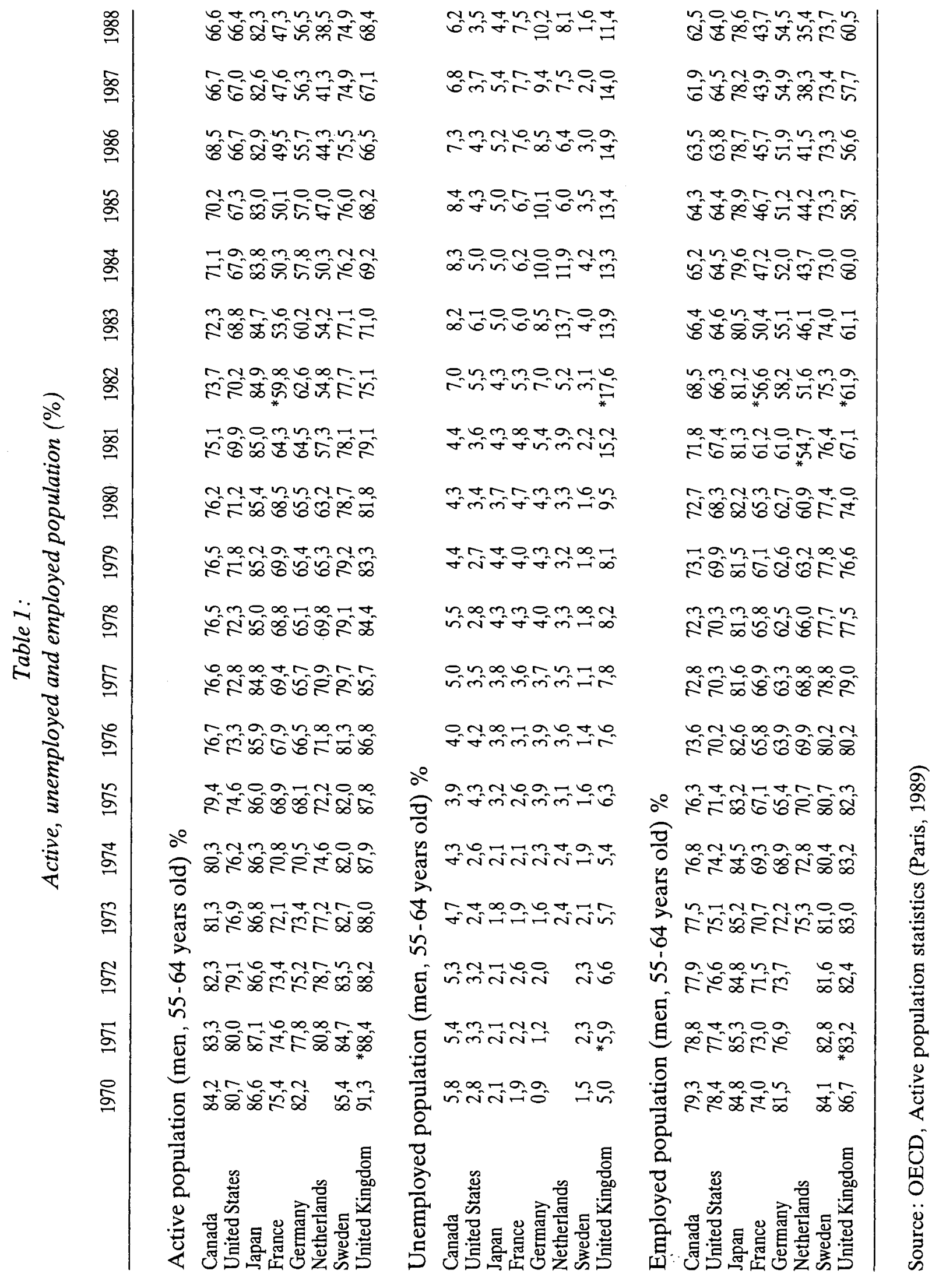


dwindle, and the individual to suffer from loss of status; continuous training tends to be reserved for younger employees; this shortening of the professional life span has proved detrimental to mobility within the enterprise. Finally, for those in the 45 to 50 years agebracket, however great their skills, finding a new job is frequently a daunting task.

It is the large enterprises - above all the industrial undertakings - which have made greatest use by far of early retirement programmes. Various surveys have shown that between 40 and $50 \%$ of early retirees came from enterprises with a work-force of over 500 , two-thirds of them in industry, with less than one third in the services sector.

For the workers concerned, the studies made in France ${ }^{1}$ show that the majority of early retirees "were in fact forced to quit"; if the choice had been theirs, they would have continued working. Only one third could be described as having "clearly volunteered for early retirement". As a general rule, manual and low-skilled workers view early retirement as a kind of release. The majority of the management staff and of professional workers, on the contrary, see themselves as the victims of a 'casting-off' process, some even as 'being committed to social oblivion'. It would, however, appear that, more recently, early retirement is giving increasing satisfaction to those who have experienced it and, as time passes, is beginning to be perceived by the public at large as a kind of "new entitlement or right".

For France as a whole, early retirement has proved expensive. Since 1983 it has cost the nation some 50 billion francs annually, ${ }^{2}$ more, that is, than unemployment benefits and substantially more than professional training. What is true of most industrialised countries where public spending on retirement has become a sizeable item in social welfare budgets, is remarkably the case in France. Indeed, it is estimated that, in 1984, public expenditure on the elderly - pensions, the funding of early retirement, medical costs, etc. - accounted for $55 \%$ of the nation's total social welfare budget and at a time when unemployment had reached record levels!

\section{9: A turning point?}

Developments over the last two or three years - major advances in the restructuring of enterprise, the upturn in economic activity and the daunting prospects of funding retirement in the future - have forced the authorities and enterprises to consider a change of direction for their end-of-career policy for the 1990's. As can be seen from the Graph 1, the age of departure from the work place - the effective point of transition to the inactive state - began to climb in 1988 to reach 60.5 years in 1989. The period separating the onset of early retirement and "joblessness" from retirement proper has now dwindled to less than two years. According to experts, this trend - although the official statistics are not available yet - has continued in 1990 and in 1991.

\footnotetext{
1 A.-M. Guillemard, "Les nouvelles frontières entre travail et retraite en France, bilan et perspectives des cessations anticipées d'activité", in La Revue de l'IRES, No. 2, Winter 1990, Paris, pp. 41-98.

2 Vieillissement et emploi, Vieillissement et travail, E. Lion, Rapport du Haut Conseil de la Population et de la Famille, La Documentation Française, Paris, 1989.
} 
Graph 1:

Evolution of retirement and early retirement ages (1981-1989)

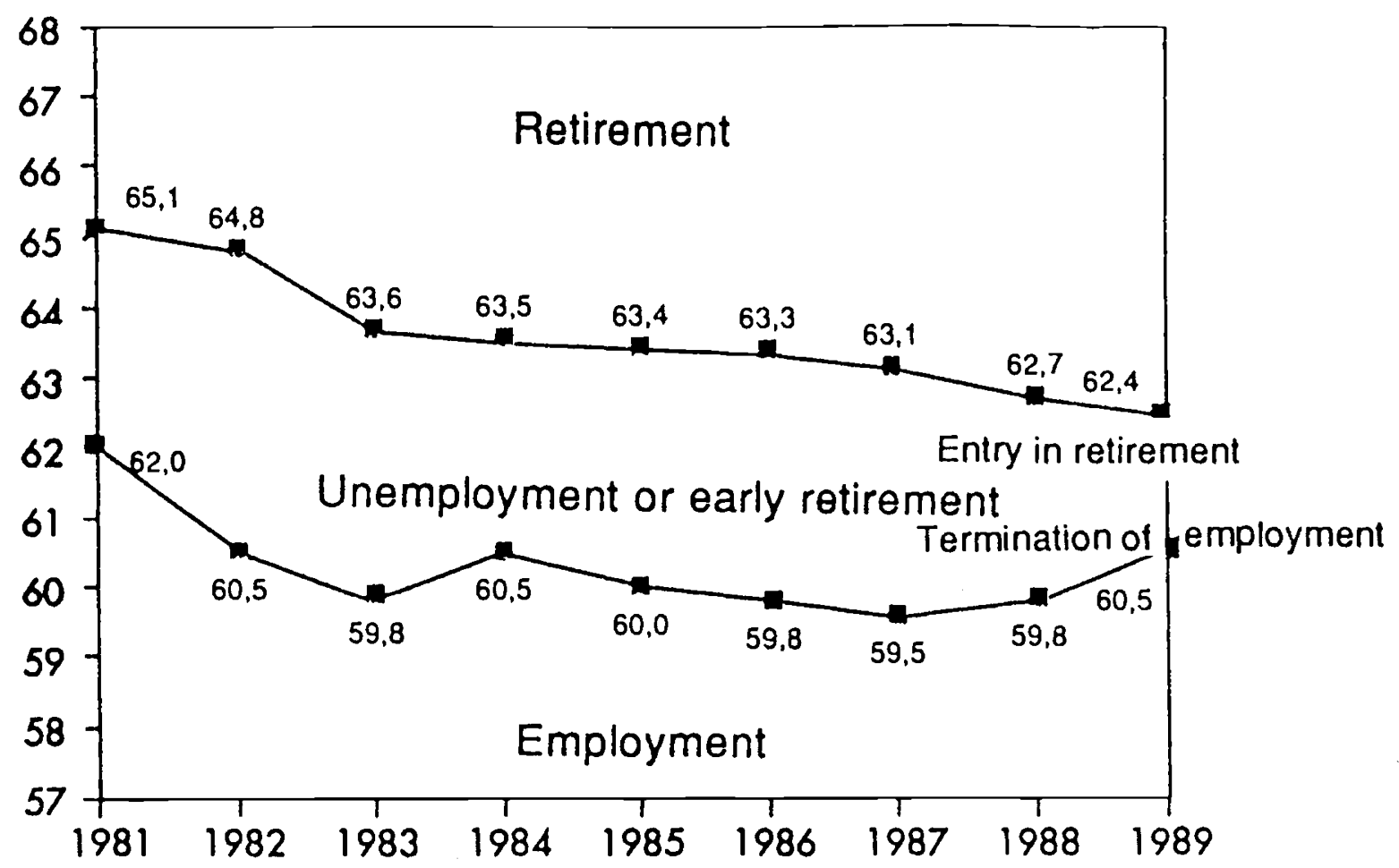

Source: Bulletin de l'AGIRC, No. 166, March 1991, Paris.

\section{Human resource management within the enterprise}

Enterprises are gradually waking up to the disadvantages of policies for compulsory early-retirement. They have begun to learn that there is a price to be paid in loss of expertise and enterprise culture for the early jettisoning of certain management staff and skilled employees. Replacing 50-60 year-olds by younger staff only postpones the problem a few years. Having carefully examined the prevailing age-pyramid structure within their undertakings, some directors foresee within 10 years a high portion of employees within the 45 55 year age-group in their work-force and are becoming convinced of the need for more balanced age-group management strategies.

Indeed, by contrast with countries like Germany, there is as yet no acute shortage of young persons reaching the labour market in France where the main problem is rather the rapid ageing of the work force: one employee in two will be over forty by 2005 instead of the current figure of $40 \%$. The evolution of the age pyramid for the working population clearly reflects this trend (Graph 2). Certain statistics express this process of ageing in a striking fashion, as for example the proportion of those in the 50-54 year age-group: which will rise from 2.145 .000 in 1985 to some 3.285 .000 by the year 2000 , an increase of $44.5 \%$. 
Graph 2:

France's active population

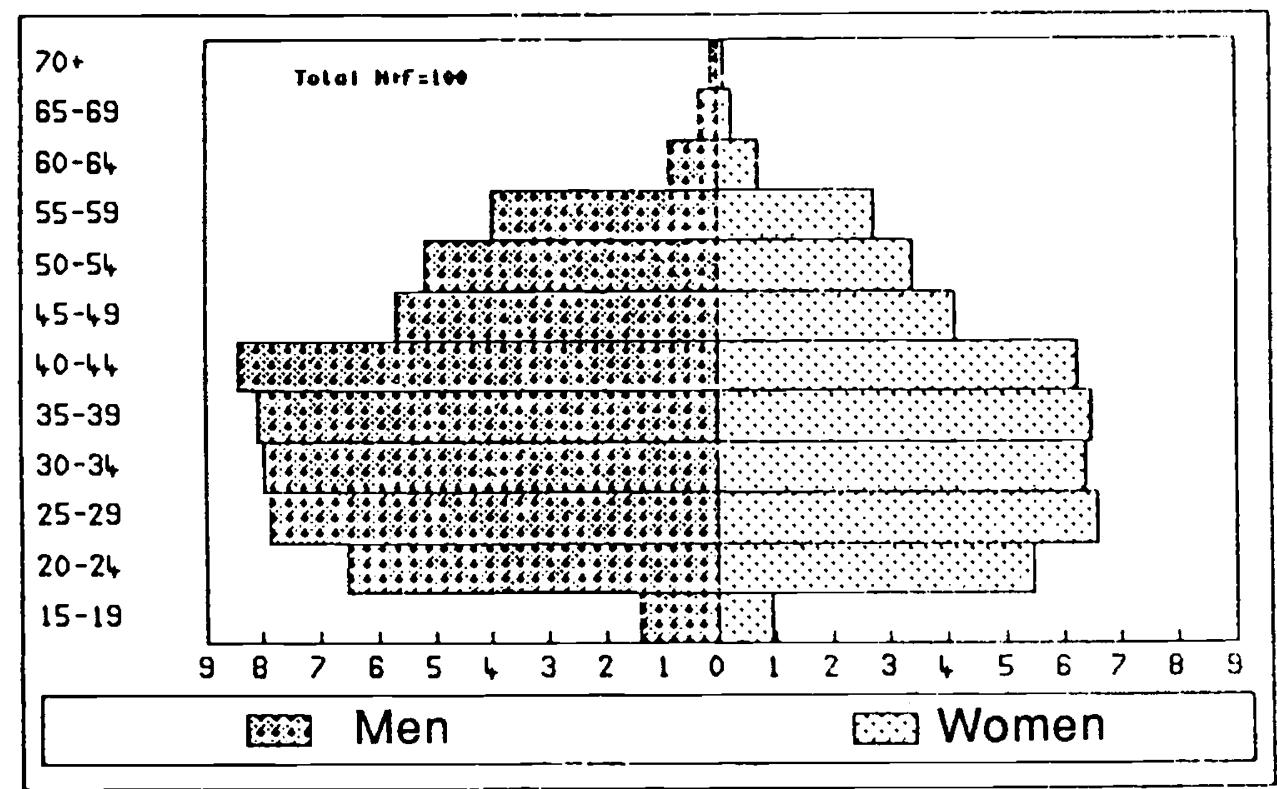

1990

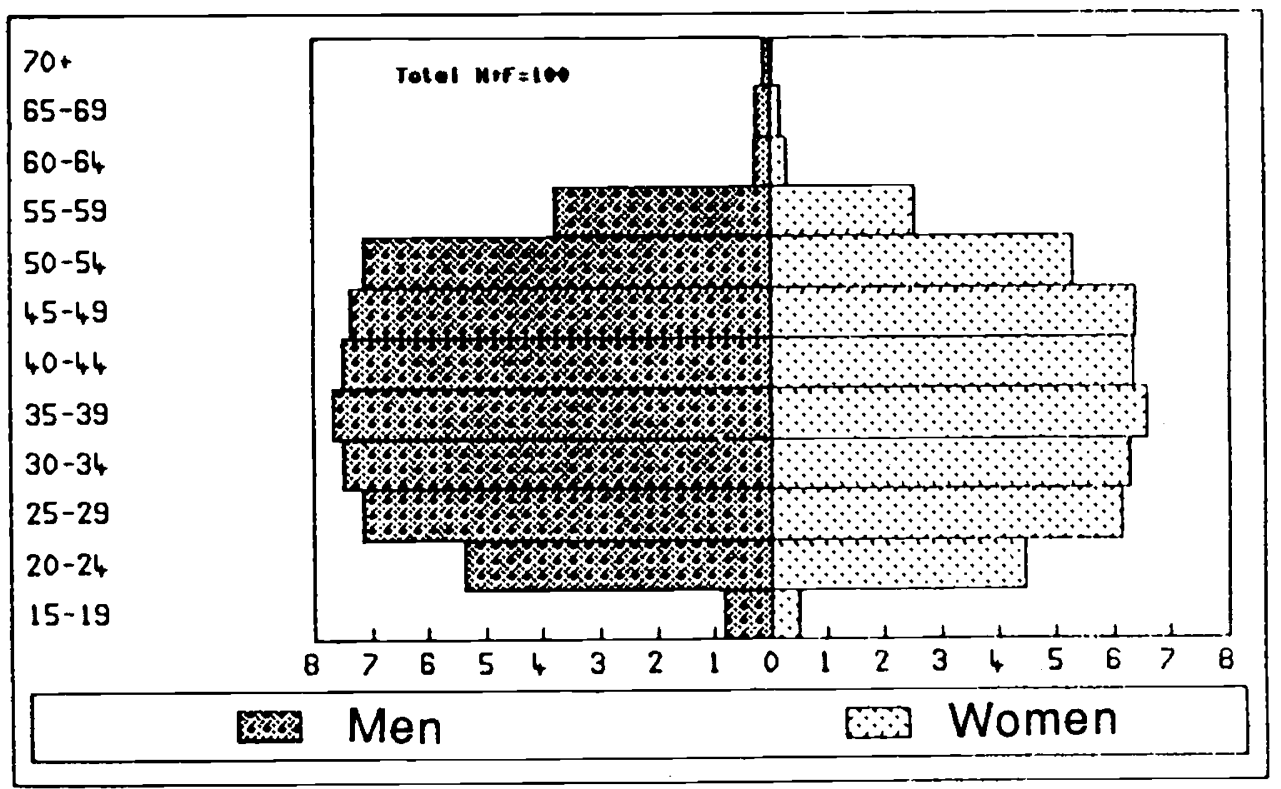

2000

Source: INSEE.

If standards of quality and efficiency are to be maintained, it will thus be increasingly necessary to sustain high levels of motivation and performance throughout the work-force in young and old alike, and hence also essential to provide for continuous training throughout an employee's working life. 
In regard to the financing of pensions in the future, enterprises are contemplating reforms to their 2nd pillar system which in France is also contribution-based; some are considering complementary schemes by capitalisation, others have already slowed down the movement towards early retirement and are devising ways of lengthening professional life. Although such trends do not as yet affect even the majority of undertakings, a new "diversification of management policies" on early retirement is beginning to emerge.

\section{Government measures}

As early as 1987 , certain steps were taken to replace the indemnisation of employees cast-off at the end of their working lives by a more positive approach.

The principal measures were designed to:

- promote through the provision of funds the extended continuous training of employees over the age of 45 (law of 1989);

- raise the cost of laying-off employees over 55 years of age (though there are still many exceptions) (law of 1987);

- facilitate the recruitment of the victims of long-term unemployment after 50 years of age by exempting the enterprise of all social insurance contributions until such time as the employee becomes eligible for a full retirement pension (law of December 1989);

- encourage part-time employment as a substitute for lay-offs on economic grounds (decree of 11 September 1989);

- promote gradual retirement (law of 5 January 1988) by entitling an employee over 60 years of age to receive a partial pension while continuing to work part-time with no age-limit being set for full retirement. Unfortunately, thusfar the demand for gradual retirement has been small (less than one thousand requests in 1989 and 1990). It should also be mentioned that since 1982 a scheme for gradual early-retirement has existed but has not proved very successful either. Thus of the 112.000 employees in the 55 to 59 year age group working part-time in 1988 , only 8.000 belonged to gradual early-retirement schemes.

Moreover, in the face of the difficult prospects for funding pensions after 2000-2005, the government is contemplating various measures:

- an implicit raising of the age of retirement by increasing the minimum number of years for compulsory social security contributions conferring the right to a full state pension from 37.5 to 40 , or even 42.5 years;

- the amount of the pension being calculated on a 25 , rather than a 10 , best wage-years basis;

- the creation of complementary pension funds by capitalisation within the enterprise or professional branch;

- the establishment of reserve funds within existing pension schemes.

\section{France's potential for the Fourth Pillar in the 1990's}

It is thus within the context of the demographic, economic and socio-cultural change we have described that the Geneva Association has undertaken a survey with a view assessing France's 4th Pillar potential. The purpose of the 4th Pillar is to enable employees reaching a certain age - 60 years in France - to combine partial retirement and part-time 
work with no upper age-limit. Such a scheme could in future years considerably lighten the burden of financing retirement which in France, as indeed in most Western countries, will become a problem and especially so as about 2005 . It would, moreover, appear to fit in with the aspirations of employees ${ }^{3}$ of the baby-boom generation, especially those with professional skills, who will be wanting to remain in touch with their professions much longer than the generation currently in full-retirement.

In the case of France, having first examined all the relevant litterature available - and this has increased enormously in recent years - the author went on to conduct in depth interviews with those responsible for human resource management in a number of undertakings in the tertiary sector (inter alia, 6 large insurance companies and two of the biggest banks) and in industry (3 large undertakings) as well as with specialists (8) in the field from various backgrounds (government, professional organisations, and research institutes).

\subsection{Favorable trends}

In general, almost all interviewees, specialists and human resource managers alike, have had occasion to begin a thorough reassessment of the end-of-career situation. They are unanimous in stressing the need for a revaluation of the end-of-career years and for personalising the process of entry into retirement. A majority feel that, for skilled employees especially, in future years provision will have to be made for extending the span of professional life, even if the full brunt of this demand will not be felt until the end of the 1990's.

Trends favorable to the 4th Pillar are to be discerned essentially in three domains: in management, in the labour supply changes of our service economies and life-cycle of employees. The summary presentation of these trends in the Graph 3 requires the following additional comments:

\subsubsection{Management}

There are 3 main factors which will tend to favour a flexible extension of the span of professional life. They are:

- continuous training to cover the end-of-career years: French firms devote enormous sums to their continuous training programme. In the firms interviewed these sums varied from $4.5 \%$ to more than $8 \%$ of the wage-costs, a substantial percentage in comparison with the amounts earmarked by British and even German firms for this purpose. Such continuous training programmes while being greatly developed during the 80 's, especially by the larger undertakings, focused essentially on the 25 - 45 year agegroup. But even now the situation is changing rapidly. Employees who in 1990 were in the 35-45 year age-group are already accustomed to continuous training and will remain motivated by it, in contrast, that is, to those currently in the 50-60 year age bracket. Interviewees were, moreover, found to be increasingly aware of the link between productivity and initial and continuous forms of training. They are already devising programmes designed to provide employees with training through to retirement age ;

- age-group management and mobility within the enterprise; thanks to the improved prospective management of employment which has begun to incorporate age-group

${ }^{3}$ See "Work and Retirement: Future Prospects for the Baby-Boom Generation," G. RedayMulvey, The Geneva Papers on Risk and Insurance (No. 55, April 1990, pp. 100-113). 
Graph 3:

Favourable trends to the 4th Pillar

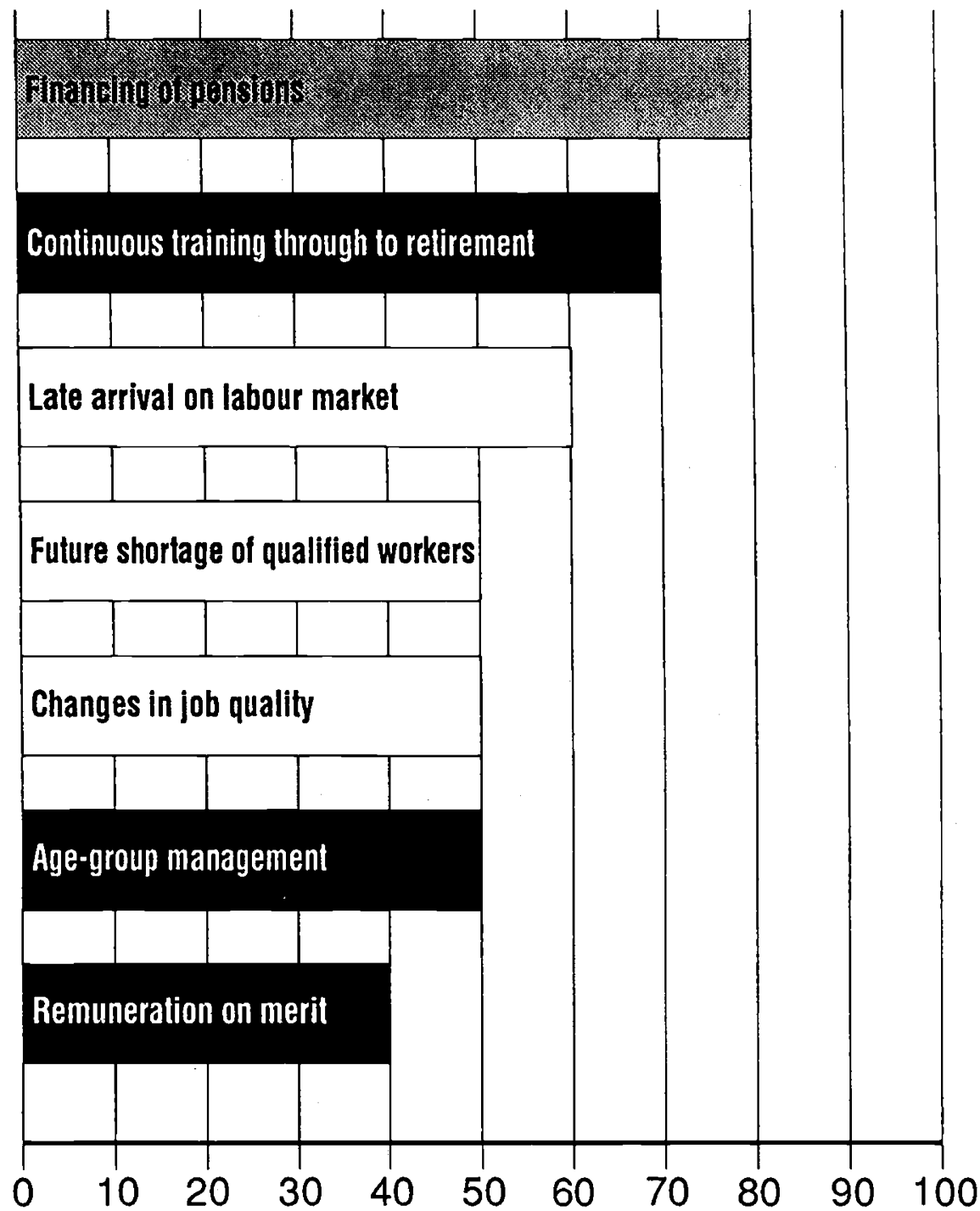

$\%$ of interviewees who have estimated these factors as FAVOURABLE

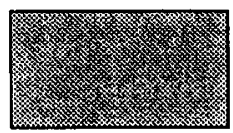

Collective

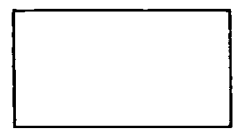

Labour market

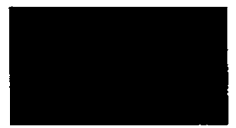

Management

management into personal policy - especially periodic career reports and the formulation of individualised career projects which often involve training - employees will have a better chance of remaining motivated and competent through the entire span of their professional existence. Age-group management in certain cases will also increase mobility within the 
enterprise by, for example, an employee being moved to a less demanding job and thus being able to maintain high professional standards until much later in his or her career;

- one of the obstacles to extending working-life is doubtless the system of seniority-based remuneration which persists even now in a large number of undertakings. One current development in a number of the undertakings interviewed - particularly the insurance companies - is to replace this traditional system by a system of performance-based remuneration (except, that is, for socio-professional categories where career prospects are severely limited) which will tend to promote a different wage-curve and hence indirectly a lengthening of professional life.

\subsubsection{The labour market supply: changes in quantity and quality}

- It is common knowledge that the labour market is about to experience a shortage of skilled workers, a phenomenon already being felt in certain sectors (e. g. computer specialists, certain categories of technicians) of the companies interviewed; in France the curve for the 15-19 year olds reaching the labour market will fall slower and later than in Germany, Italy and the United Kingdom; almost all interviewees were of the opinion that this shortage will lead to a "de facto" extension of professional life; indeed the undertakings we interviewed, in attempting to stem the trend towards early retirement, are already returning to the legal retirement age and feel that within a few years an extension beyond 60 years will be needed, at least for management and professional personnel.

- Jobs standards are evolving rapidly everywhere and this applies particularly to services; thanks to the new technologies and to advances with the reorganisation of work, one may safely assert that most jobs today are physically less demanding, are increasingly intellectual in content and involve a range of functions or tasks far better-integrated than only 10 or 15 years ago; these changes in job quality and task patterns are bound to benefit employees after 60 years by helping them to maintain their standards of productivity; they will also produce a wide range of activities which may conveniently be exercised on a part-time basis. More than half of the interviewees concurred these assertions.

\subsubsection{The professional life-cycle and the aspirations of skilled workers}

- It is an establised fact that with the lengthening of schooling in France - continuing later than in many neighbouring countries - young persons are entering professional life older. The employment rate for the 15-24 year age-group has thus declined substantially from $47 \%$ in 1975 to $30 \%$ in 1988 and this trend is continuing. Now, the minimum requirement for entitlement to a full-pension (to be set at least at 40 contributions-years) will mean that employees of the baby-boom generation - especially those who have gone on to higher studies or entered their first job around 23-24 years - will be obliged to extend their working life several years beyond the legal retirement age of 60. This decision will not be a matter of choice but a financial necessity.

- Furthermore, a fixed life-cycle divided into 3 periods - youth and education, adulthood and work, retirement and leisure - will now tend gradually to be replaced by a more flexible and personalised cycle: a flexible working-life for some, increased leisure time, more time devoted to training throughout one's professional life, periods of unemployment, sabbatical leave, active retirement, etc. There is today general agreement about 
the need for a transition period between full-time employment and full-retirement. The baby-boom generation - especially qualified employees, something which a number of opinion-polls have confirmed - will tend to keep in active touch with their professions until later in life. As D. Kessler has rightly put it: "The utility of leisure and retirement relative to that of work will tend to diminish..." 4

While the potential for the 4th Pillar will in future years depends as much on the trends we have just described as upon the current obstacles we shall be considering below, there are nonetheless enormous differences from one professional category to the next. The Graph 4 summarises the results for the insurance and banking companies we interwied.

\section{Graph 4:}

\section{Jobs and their 4th Pillar potential}

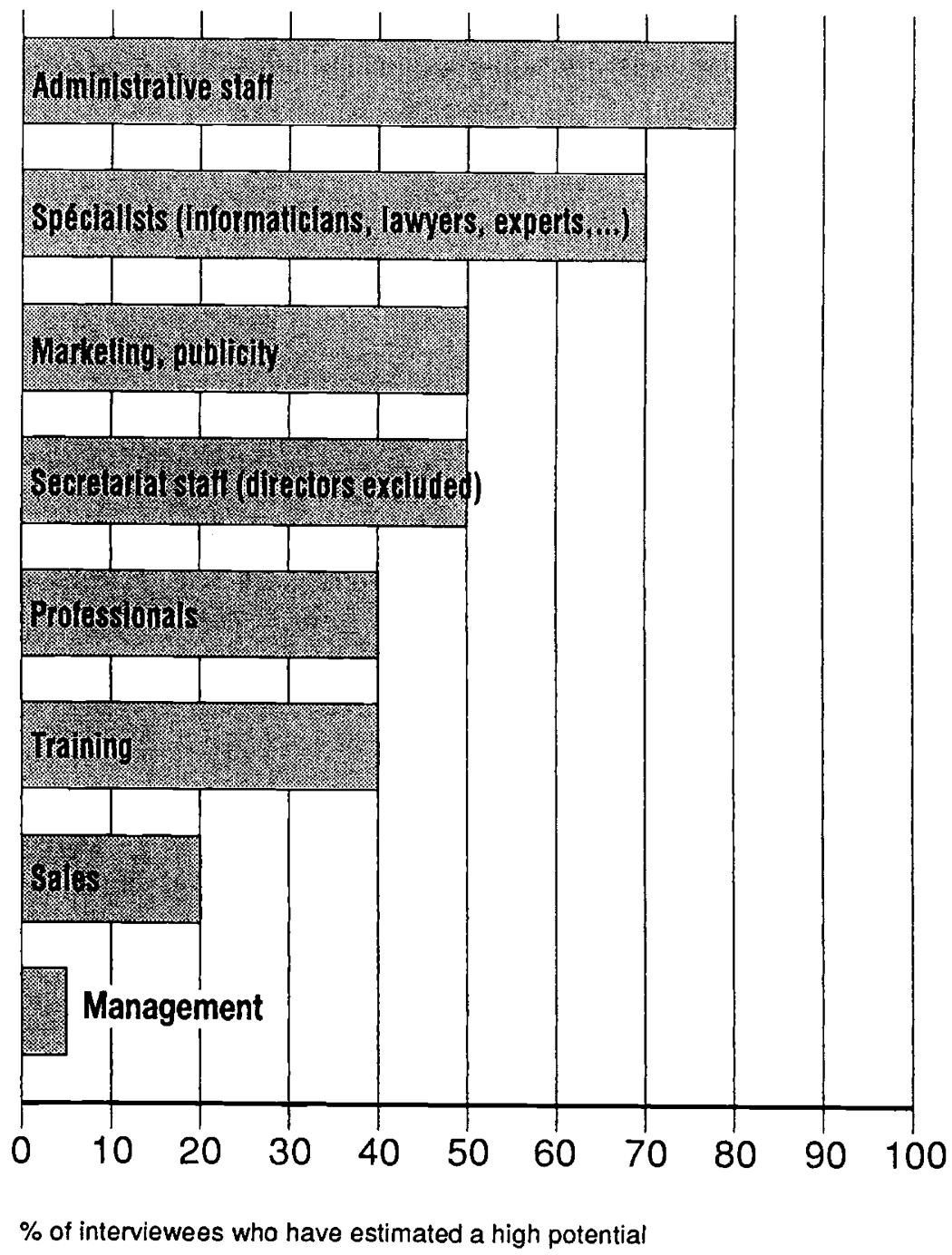

4 D. Kessler, "Les Quatre Piliers de la Retraite", Etudes et Dossiers no 144, March 1990, The Geneva Association. 


\subsection{Current obstacles}

The main obstacles to the 4th Pillar we were able to identify during our interviews with the enterprises visited are of 3 kinds: some of these obstacles have to do with the management in the enterprise, others with current collective regulations, and yet others are personal in nature. They are summarised in the Graph 5, but require the following brief comments:

\section{Graph 5:}

Current obstacles to the 4th Pillar

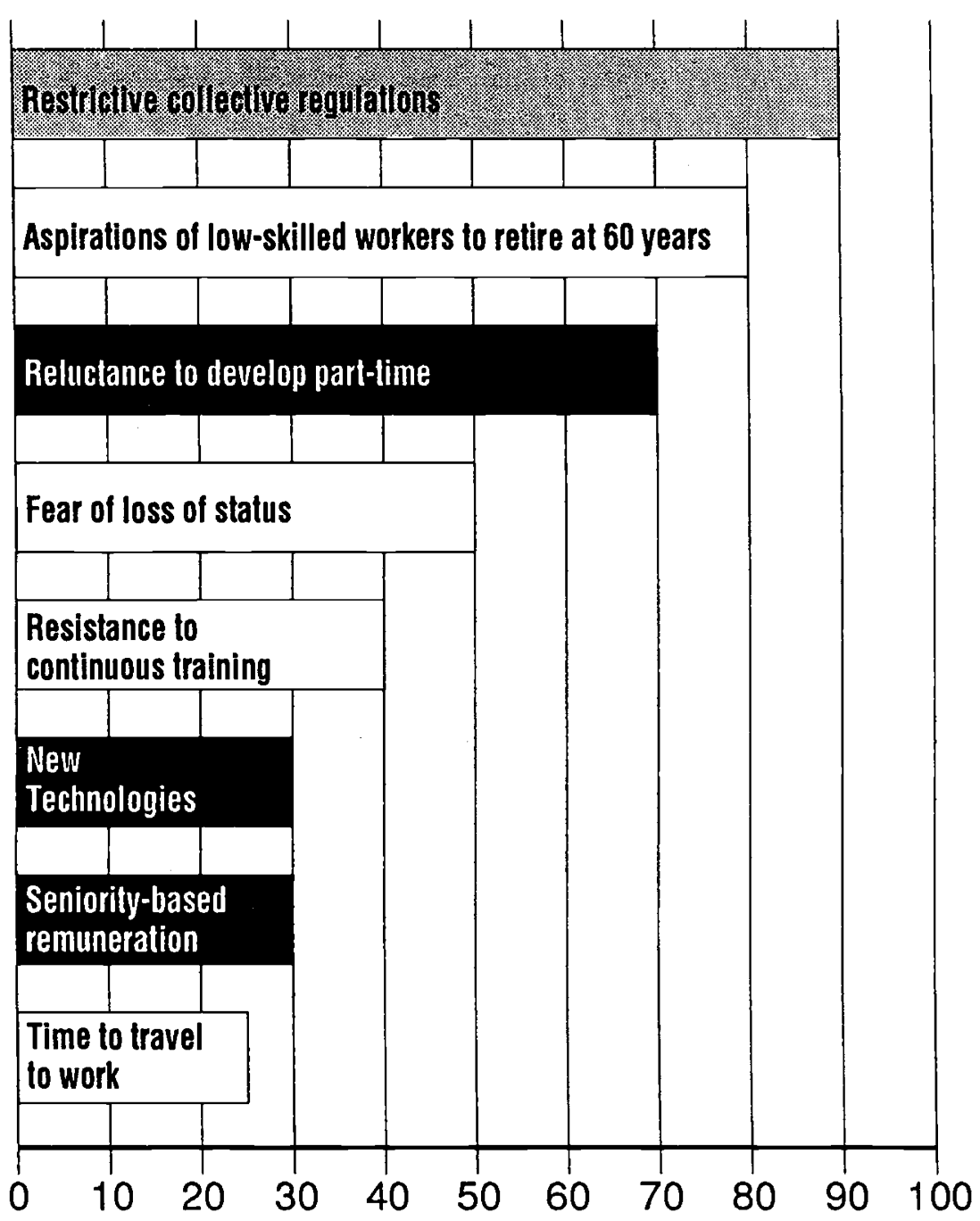

$\%$ interviewees who have estimated these factors as current obstacles

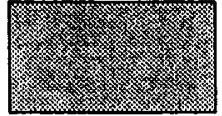

collective

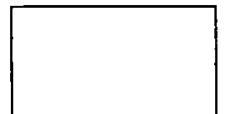

personal

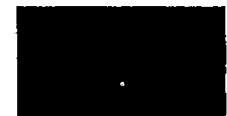

management 


\subsubsection{Management}

- The main obstacle here, and it is a sizeable one, is the very great reluctance of French firms - in contrast especially with anglo-saxon, Dutch and nordic enterprise - to develop part-time work. In the undertakings interviewed, part-time work increased slightly during the 80 's and has tended to level off around $10 \%$ of overall employment in enterprise in the tertiary sector with a marginally lower percentage in industry. No undertaking recruits parttimers and only a few have part-time promotion policies; it remains essentially a facility for mothers with families or for women, rarely for men, reaching the end of their career, and is used above all in medium and low-skilled administrative jobs, and very occasionally by professional and management staff. Interviewees for this survey, however, do consider part-time work to be more productive and do not see it as causing any major organisational problems. At a time of increasingly mobile and diverse production policies, when employees are becoming increasingly autonomous and multidisciplinary in the skills they handle, work patterns timewise remain as rigid and monolithic as ever. Within the management hierarchy and within the work-force itself there is still strong resistance to part-time work. In short peoples' attitudes towards the latter continue to be dominated by negative cultural prejudices.

- The prevailing system of seniority-based remuneration remains an obstacle to developing the 4th Pillar, but, as we saw in 2.1.1. above, this situation is beginning to change.

- Finally the new technologies which as a general rule enhance job autonomy are also seen by $30 \%$ of those interviewed as obstacles to an extension of working-life in that they normally lead to job reductions. This is, however, a factor which was probably more relevant for the 80 's than for the years to come.

\subsubsection{Collective regulations}

Over the past 15 years or so, the various measures on early retirement, end-of-career or compensation for the "elderly" unemployed have meant enormous financial benefits for the individuals concerned. There exists today no real financial incentive to work beyond the legal age for retirement or beyond age-limits established under negotiated settlements for the professional categories. Quite to the contrary, prevailing regulations on, for example, cumulative wage-pension arrangements, are very restrictive and specifically prohibit the receiver of a pension from continuing to work in the same undertaking (although this specific regulation, as it happens, does not apply to the gradual retirement we referred to above). In a word, therefore, as things stand, the law - although changes will doubtless be made in the near future - provides the wage earner in France with absolutely no incentive to work beyond the retirement age. And in the rare instances where legal provisions to this end do exist, as, for example, is the case with gradual retirement, either enterprise is ignorant of them or the provisions themselves are too complicated, or both!

Moreover, most negotiated settlements (of insurance companies and banks for example) establish 65 years as the upper age-limit for all remunerated work.

\subsubsection{Obstacles of a personal nature}

They are of 3 kinds: the aspirations of employees, fear of erosion of status, and, in a fair proportion of the work-force, an inability to adapt to continuous training.

- The desires of employees in the undertakings visited: at present, the vast majority of employees are quite content to retire at 60 , if not before. Many belong to a generation 
which has provided long service within the enterprise and which is possessed of no great professional skills. After a long and arduous working-life, retirement for many come as a well-deserved release. Today, retirement at 60 is felt to be everyman's entitlement and cultural attitudes in France will have to change before workers come round to accepting the idea of extending professional life any further. Nonetheless, as we saw in section 2.1.3., attitudes vary from one generation or professional level to the next, and the public's perception of the desirable balance between work and leisure is beginning to alter...

- Age-group and career management which accompanies end-of-career changes is designed to increase mobility of employees within the enterprise. This of course involves among other things job adjustments for employees approaching retirement. The 4th Pillar, because of emphasis it places on part-time work patterns, will inevitably give rise to fears about erosion of status. While survey samples to date ${ }^{5}$ would appear to indicate that employees are ready to move to more flexible, less demanding jobs, even to work part-time in prolonging their careers, $40 \%$ of those human resource managers interviewed are even so convinced that fear of status will be a factor to be very careful to, and in some cases an obstruction.

- Finally, some categories of employees, especially those with low or medium skills, have displayed psychological or mental resistance to continuous training, especially during the years approaching retirement. Even though such attitudes are likely to change, they do, nevertheless, demonstrate the importance of psychological factors in continuous training which thus far have probably not received sufficient recognition.

\subsection{Action needed}

There are two kinds of actions to be taken if the 4th Pillar is to be developed to any appreciable extent within firms in France. The first relates to enterprise management and the emergence of role models, the second to national legislation on pensions.

\subsubsection{Government measures}

The first task would be to review the statutory provisions in this field since the law should lay very much more emphasis both on a transition period between full-time employment and full retirement as also on an extension of working-life based on flexible and parttime work patterns. But the mere fact of having laws is by itself not sufficient. The latter must be "catalitic", that is, clear, simple and accompanied by the requisite information and publicity apparatus. Moreover, financial incentives must be made sufficiently attractive so as to "reverse the trend of the 80 's".

The White Paper issued by the Premier Ministre at the end of April 1991 appears not to run counter to the 4th Pillar. The government measures mentioned in Part 1 are also a step in this direction. Nonetheless, if highly stereotyped behaviour patterns and perceptions of retirement are to evolve, it is a significant and properly coordinated set of measures that will have to be taken. Moreover, it is perhaps the public service departments which should take the lead and set the new trend by encouraging innovative experiments in the part-time based extension of working-life.

${ }^{5}$ Gaulier \& Thomas, Modernisation et Gestion des Ages: Les Salariés Agés et l'Emploi, La Documentation Française, 1990, p. 160. 


\subsubsection{What enterprises can do}

The action to be taken by enterprises must essentially consist in changing attitudes towards, and policies on, part-time work; in improving mobility within the enterprises and in the more widespread use of viable role models. Indeed, the results of this survey, which is explorative in nature, have served to convince its author that, if a certain number of firms could establish programmes for managing the extension of working-life beyond 60 years on the 4th Pillar lines, such initiatives would have a snowball effect. Given that relations between the social partners in France are crucial, care must be taken to involve the unions (some of whom appear to be by no means adverse to this kind of policy) and to persuade them of the sound sense of what is contemplated. For the 4th Pillar must be presented to the public as being beneficial to employee and employer alike, and because of its contribution to the funding of retirement and positive effects on mental health and social integration of people, of interest to the community at large.

\section{REFERENCES}

CONSEIL ECONOMIQUE ET SOCIAL, Les Conséquences du Vieillissement de la Population Active, Rapport de M. Garibal, Juin 1990, Paris.

GAULLIER, X. and THOMAS CL., Modernisation et gestion des âges - Les salariés âgés et l'emploi, La Documentation Française, Paris, 1990.

HAUT CONSEIL DE LA POPULATION ET DE LA FAMILLE, Vieillissement et emploi, Vieillissement et travail, E. Lion, ed. La Documentation Française, Paris, 1989.

KESSLER, D., Les Quatre Piliers de la Retraite, Etudes et Dossiers, March 1990, The Geneva Association.

GUILLEMARD, A.-M., "Les nouvelles frontières entre travail et retraite en France, bilan et perspectives des cessations anticipées d'activité", in La Revue de l'IRES, no 2, Winter 1990, Paris, pp. 41-98.

THE GENEVA PAPERS ON INSURANCE, STUDIES ON THE FOUR PILLARS, no 55, April 1990, Geneva, mainly Kessler D. and Reday-Mulvey G. articles.

THE FOUR PILLARS, Bi-annual Research Bulletin, The Geneva Association, Nos 4-10,1986-1991. 